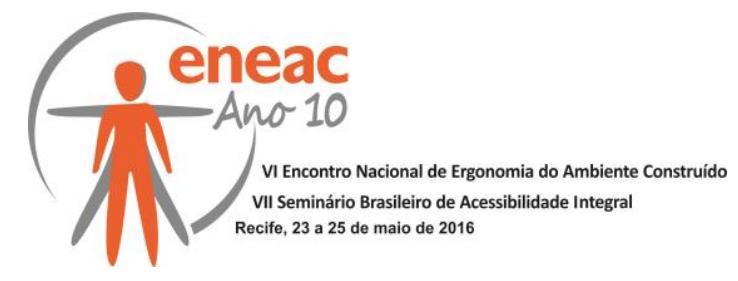

\title{
ERGONOMIC DESIGN OF BUILT ENVIRONMENT
}

\author{
ATTAIANESE, Erminia (1) \\ (1) University of Naples Federico II - Dept. of Architecture and LUPT Interdept.Research \\ Centre, Assistant Professor of Architectural Technology \\ Email: erminia.attaianese@unina.it
}

\section{INTRODUCTION}

Over the last 50 years, ergonomics/ human factors (HFE) discipline has been evolving as a distinctive area of knowledge focusing on the nature of human-artefact interactions, viewed from the unified perspective of the science, engineering, design, technology, and management of human-compatible systems, including a variety of natural and artificial products, processes, and living environments [1]. According to a wide discussion within researchers and ergonomic scientific associations [1] the main goal of HFE is today understand interactions between people and everything that surrounds us, and based on such knowledge to optimize human well-being and overall system performance. It discovers and applies information about human behaviour, abilities, limitations, and other characteristics to the design of tools, machines, systems, tasks, jobs, and environments for productive, safe, comfortable, and effective human use, in order to increase the effectiveness and efficiency with which human activities are conducted as well as to improve the general quality of life $[1,2]$.

So, one of the distinguishing features of the HFE discipline and profession, together with the fundamental understanding of the interactions between people and their environments, is an understanding of how human-system interactions should be designed, since HFE has positioned itself as a unique, design-oriented discipline. Design is one of the paradigms of HFE discipline, and is concerned with the ability to implement knowledge about human-systems interactions, as previously identified, described, assessed and modelled, and use them to develop systems that satisfy customer needs

\section{CORE CHARACTERISTICS OF ERGONOMIC DESIGN.}

HFE has a unique combination of three fundamental characteristics: it takes a systems approach, it is design-driven and it focuses on two closely related outcomes: performance of designed system and well-being of people using them [3]. User-centered design methodology is the application of ergonomics to design, which core is design whatever system, focusing on users [4,5]. Essential element of user-centred design are the active involvement of users and a clear understanding of user and task requirements; an appropriate allocation of functions between users and technology; iteration of design solutions in a multi-disciplinary frame [6]. In fact these elements result from the application into design activities of ergonomic general principles, expressing through key concepts as follows [7]:

empirical approach, as design choices and decisions are founded on controlled qualitative and quantitative data, gathered by actual users psycho-physical characteristics [8];

iterative dimension, as design development is a non-deterministic cyclic process, each phase of which proceeds experimentally, testing alternative solutions based on the lessons learned about the performance of the previous one [9]; 


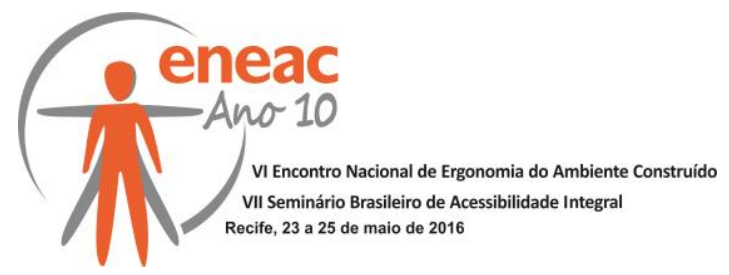

- participation, since subjective aspects of human-system interaction are highlighted and interpreted both as design inputs and feedbacks [10];

- non procrustean vision, given that real users goal and expectancies are focused, observing people as they are rather then they might be [10];

- human variability and diversity focused, since cultural, social, physical differences of users are emphasized and not standardized [11];

- pragmatic, as the selection of design priorities are the most effective for users and are made by users involvement ;

- system oriented and human activities oriented: since the observations are based on the specific interactions between people and all other elements within a system. Contextualization is taken into account; different aspects of the person (physical, physiological, psychological and social) and different aspects of the environment (physical, social, informational, etc.) are considered; issues on various system levels from micro-level (e.g. humans using tools or performing single tasks) to meso-level (e.g. humans as part of technical processes or organisations) to macro level (e.g. humans as part of networks of organizations, regions, countries, or the world) are addressed, recognizing that the system changes and modifies its state and the inter-actions within it in the light of circumstances and events $[3,4]$.

\section{HFE ISSUES IN ARCHITECTURE}

One of the basic element of the ergonomic/human factors approach is the adoption of an anthropocentric point of view in observing relationships between people, systems and environment. The human consideration in architecture design may appear obvious and not new, but designing at human scale (i.e. design with the people in mind) may be seen as no more than a slogan since during the time only partial aspects of human nature have been usually considered by architects, mainly related to body average sizes or to stereotyped behaviours of inhabitants, paying no attention to differences, nor to mental aspects about perception and cognition processes, and underestimating the true impact of the built environment on person's level of functioning, degree of independence and psycho-physical well-being [12] .

History of architecture is full of examples showing the ambition of architects to shape buildings on the proportions of the human body, in the belief that the beautiful form was the one in which the people could live better, such as Vitruvius architectural orders, dimensioned in relation to human size, or Renaissance buildings, where a complex dimensional system should have represented the idea of an anthropomorphic space, and so on, up to the case of Modern Movement case, when, for example, the principles of the "Existenzminimum" or modulor, inspired architects rationalists to theorize a fixed size suitable to the main living functions, for an optimum housing dimensioning.

Only from the 1960s this anthropocentric model gradually began to change, thanks to bioclimatic approach and regionalism in architecture, in which human body was interpreted as a complex of physiological and psychological reacting system to environmental stimuli during built environment fruition [13].Moreover, almost in the same years, the growing field of environmental psychology proposed models of physical setting pressing on man [14], which significantly supported the studies about the welfare of confined spaces, particularly focused on the relationship between the physical parameters of an environment, the physiological parameters of people and the perception of wellbeing expressed by the people themselves, successively transformed in technical standards for thermal comfort in built environment [15]. Such studies integrated the healthy buildings approach, started by hygienists in the 18th century that identified consequences of urban spaces insalubrities and evolved in energy conservation measures introduced in housings after the oil crisis in the early 1970s and in subsequent indoor air quality questions [16]. Then the concept of Universal Design, since the early 1980 s, focused the design on human diversity, in order to define how built environment and products should be realized to result aesthetic and usable to the greatest extent possible by everyone, regardless of their age, ability, or status in life [12]. 


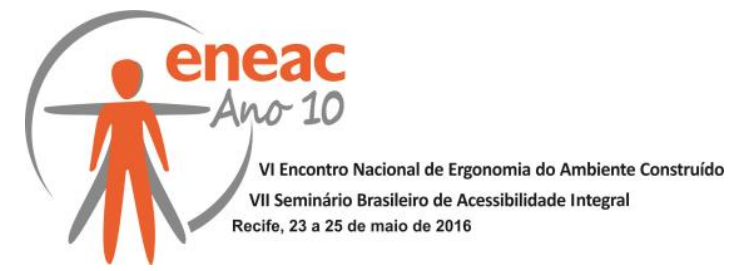

More recently, according to the cultural approach of companies quality assurance and management, the idea of a building global quality assessment criteria in organizational context emerged [17], bringing the need of metrics for considering the use value of buildings in business. And it was in this context that usability studies came forward from industrial sector, since it is concerned with a building's ability to support the user organisation's economic and professional objectives. Users point of view become key stakeholder perspective in design process, especially in productive buildings or in working environment, where easy and fast to learn, efficient to use, easy to remember, allow rapid recovery from errors and a high degree of user satisfaction offered by built environment are considered crucial [18]. Social practices in design, evoked by the focus on user perspective, are today frequently applied in building post occupancy evaluation (POE) and in participatory design of public spaces [19].

\section{HUMAN-CENTERED DESIGN OF BUILT ENVIRONMENT}

By an ergonomic perspective, built environment may be considered as a facility able to support people acting in and around it during their everyday life. Thus main objective of ergonomic design for the built environment, as any other tool, is to balance dual outcomes: system performance and human well-being. Human well-being has been defined as a systemic and holistic measure which integrates many facets including the physical, cognitive and psychological needs of people; it is connected with overall satisfaction, happiness and quality of life, and consistent with how WHO states about health [20].

As studies on occupants in productive buildings demonstrate, well-being is conditioned by the quality of human activities in built environment since it may favour or hamper people in their tasks due to the effects of a whole of human perceptions, including physiological, physical, social and psychological reactions to the environment in different situations. The environmental discomfort, for example, produces a decrease of physical and mental individual capacities with the consequent increase in the levels of risks exposure for safety [20]. Ergonomic is frequently expressed as quality in use, associated to three key performance areas: accessibility, as prerequisite for basic use; usability, as use optimization and safety, as control of the consequences of use [21]. Moreover a more comprehensive frame of usability of architectural space has been recently reviewed, and objective and subjective dimensions of built environment proposed [22].

Finally since a sustainable building is meant to be a building that contributes, through its characteristics and attribute, to a sustainable development by assuring, in the same time, a decrease of resources use and environmental impact and an increase of health, safety and comfort of the occupants, sustainability goals can be successfully comprise within ergonomic outcomes of built environment [23]. According with ergonomic principle mentioned above, human centred design of built environment addresses an holistic approach structured in three macro-activities [24]. The first one is aimed to the context of use specification, by identifying the users, in physical and organizational terms, and the tasks they need to perform using the artefact. The design briefing is finalized to gather functional goals and environmental context, particularly elicited by different customers expectations, considering the entire building life cycle, since human factors implications affect both use and construction stage.

Moreover maintenance and operation performance have been assumed as necessary to assure the continuity of building and infrastructures performance, also in terms of sustainable management, despite maintainability requirements are rarely elicited in design process [25]. A particular attention has to be reserved to users analysis in order to define users profiles and clusters setting, by considering specific aspects such as: personal factors (age, sex, physical characteristics, etc.), cognitive factors (intellective abilities, skills, motivations, etc.) and behavioural factors. This sort of user survey requires techniques and data collection methods to be applied, both analytic and empiric, so that by the wide range of data gathered, all users needs can be truthfully depicted. 
